\title{
Altruism, costly signaling, and withholding information in a sport charity campaign
}

\author{
JUDIT MOKOS ${ }^{12}$ and ISTVÁN SCHEURING ${ }^{12 *}$ \\ ${ }^{1}$ MTA-ELTE Theoretical Biology and Evolutionary Ecology Research Group, 1117, Budapest, Pázmány P. sétány 1/c., Hungary \\ ${ }^{2}$ Evolutionary Systems Research Group, Centre for Ecological Research, 8237, Tihany, Klebelsberg Kuno u. 3., Hungary
}

(Received: 07 Mar 2019; accepted: 03 Dec 2019)

\begin{abstract}
Are more generous altruists more likely to signal their altruism? According to the theory of costly signaling, altruists signal their altruism in order to enhance their reputations; this theory predicts that above-average altruists will be most likely to signal their altruism. However, previous empirical research has found that average altruists are more likely to signal their altruism than above- and below-average altruists, suggesting adherence to an egalitarian norm. Studies of real-life of altruism, reputation management, and signaling are rare. Here, we examined a sport charity database to look at the behavior of donors and fundraising runners. We observed that average donors are the most likely to publish both their names and the amount, whereas below-average donors are more likely to publish only their name (and hide the amount), and extremely generous donors are more likely to publish only the amount (and hide their name) than less generous donors. We also found that runners who targeted a higher sum or a longer distance garnered larger sums through larger individual donations. These results support egalitarian theories of signaling and show that humans actively manipulate the information about their altruistic act to maximize their reputation.
\end{abstract}

Keywords: altruism, costly signaling, reputation, social norm, sport for charity

\section{INTRODUCTION}

Our ancestors lived in small groups in which the fitness of individuals depended strongly on the help of fellow group members (Aiello \& Dunbar 1993; Clutton-Brock 2009; Gintis et al. 2003; Hamilton et al. 2007; Hill \& Dunbar 2002; Nowak 2006; Shreeves \& Field 2002). Consequently, recognition of potentially helpful and cooperative partners provided adaptive benefits, and this, in turn, required the ability to evaluate groupmates according to their degree of cooperativeness (Sznycer et al. 2018). Indeed, humans are exceptionally sensitive in recognizing the cooperative willingness of their group members and estimate their reputation on the basis of this information (Milinski 2016; Milinski et al. 2001; Nowak \& Sigmund 1998, 2005; Wedekind \& Milinski 2000). In addition, humans spend a remarkable amount of time gossiping to exchange information about the norm violations of others (including non-cooperative behavior) and in turn, to build up their own reputation (Engelmann \& Fischbacher 2008; Jacquet et al. 2011; Nakamaru \& Kawata 2004; Ohtsuki et al. 2015; Seinen \& Schram 2001). Furthermore, individuals with a good reputation receive more help from the group, are healthier, and enjoy a higher rate of reproductive success. (Arnocky et al. 2016; Kaplan \& Hill 1985; Milinski et al. 2002a, 2002b; Post 2005; Wedekind \& Milinski 2000).

Several studies have investigated the reputationenhancing behavior under laboratory conditions in classic evolutionary games and showed that subjects are more cooperative or altruistic if their action is public, presumably because cooperation or altruism enhances the subject's reputation (Cuesta et al. 2015; Hardy \& Van Vugt 2006; Jacquet et al. 2011; Milinski et al. 2002b; Wedekind \& Milinski 2000). Other laboratory experiments showed that humans use altruism to compensate if they feel that their reputation is lower than other group members' reputations (Engelmann \& Fischbacher 2008; Seinen \& Schram 2001; Wedekind \& Braithwaite 2002). Interestingly, not only altruism directed at peers but also charitable giving to socially supported goals is suitable for increasing reputation (Bereczkei et al. 2007; Wedekind \& Braithwaite 2002). Moreover, a charitable donation has stronger influence on reputation than a donation to group members (Milinski et al. 2002a).

While most laboratory investigations have come to the same conclusion, these results require careful interpretation. Firstly, experiments usually involve a small sample of people from western, educated, industrialized, rich, democratic (WEIRD) countries, and the subjects tend to be university students (Henrich et al. 2010). Secondly, experimental subjects are pre-selected, since altruistic indi-

*Author for correspondence. MTA-ELTE Theoretical Biology and Evolutionary Ecology Research Group, 1117, Budapest, Pázmány P. sétány 1/c., Hungary; istvan.scheuring@gmail.com.

This is an open-access article distributed under the terms of the Creative Commons Attribution 4.0 International License (https://creativecommons.org/licenses/by/4.0/), which permits unrestricted use, distribution, and reproduction in any medium, provided the original author and source are credited, a link to the CC License is provided, and changes - if any - are indicated. (SID_1) 
viduals are more likely to volunteer for experiments (List \& Levitt 2005). Thirdly, human behavior strongly depends on the context. Even small modifications in the experimental set-up (e.g., what the game partner is called, "opponent" or "partner") could influence the reaction of subjects (List \& Levitt 2005). Other minor changes in the conditions such as the gender of the experimenter, or a light tap on the shoulder before the experiment can cause significant differences in the subjects' cooperativeness (Hagen \& Hammerstein 2006; Kurzban 2001). Since reputation depends on the observation of the act, humans tend to display more cooperative behavior under observation. Even stylized eyes on the screen can cause this effect (Bateson et al. 2006; Haley \& Fessler 2005, but see Northover et al. 2017). Lastly, and probably highly relevant, in contrast to the general experimental set-up, humans have never experienced a strong evolutionary pressure on interacting cooperatively with others anonymously; therefore, we can assume that it is not the part of normal human behavior (Hagen \& Hammerstein 2006). Voors et al (Voors et al. 2012) showed that the results of a laboratory public good game do not correlate with the subjects' behavior in a real-life situation. Despite the above-mentioned problems, dozens of lab experiments have investigated the relationship between human altruism and reputation, while only a few similar studies have been performed in a non-laboratory environment. These nonlaboratory investigations created real-life type situations in which subjects did not know that they were under scientific observation (Bateson et al. 2006; Bereczkei et al. 2007, 2010; Ekström 2011; Ernest-Jones et al. 2011; Francey \& Bergmüller 2012; Knafo et al. 2009; Winking \& Mizer 2013). The common conclusion of all these studies is that humans are more helpful if they think that others are observing them.

Only one research group has investigated the relationship between altruism and reputation in a real-life situation (Raihani 2014; Raihani \& Smith 2015). They analyzed data from online fundraising websites. One of their studies shows that males use charitable donation to compete for reputation: males give more generous donations to more attractive female fundraisers and also donate a higher amount after a large donation given by another male, while this phenomenon was not observed among females (Raihani \& Smith 2015). Another study examined data from a website where donors were given a choice whether to publish the amount they donated next to their name (Raihani 2014). An important limitation of this study is that donors only had the option to publish their name; the amount automatically appeared on the webpage. Donors prefer concealing their name when they make extremely low or high donations, while average donations were usually published. Raihani reasons that humans tend to follow group norms and therefore prefer to publish their name for average donation but tend to hide it if donation deviates from it. On the one hand, the intuitive assumption that the higher the cost of the altruistic act, the stronger the willingness to share information about it, is an attractive option. On the other hand, humans have strongly egalitarian evolutionary background and a high degree of willingness to follow social norms (Dawes et al.
2007). Contributing less or more than others could be understood as violating social norms that could lead to social punishment (Fowler et al. 2005). Experimental studies have shown that in an altruistic or cooperative situation, both free-riders and over-contributors were more likely to receive social punishment than average contributors (Bahry \& Wilson 2006; Herrmann et al. 2008; Irwin \& Horne 2013; Parks \& Stone 2010). Raihani's results reveal an important aspect of altruism: too low or too high a level of donation does not sufficiently increase the donor's reputation.

In this paper, we examine data from a sport charity campaign in which donors can choose to publish their name and/or the amount they donated. Thus, the reputation management strategy of the donors could be studied in detail, and the results obtained by Raihani (2014) could be tested. In this study, the fundraisers run for charity, and runners published their target distance and the target sum they hope to raise. It is therefore possible to study whether the target distance and target sum have an effect on the realized donation sum and compare these results to those of previous studies (Cryder et al. 2013; List \& Lucking-Reiley 2002). The following hypotheses were tested:

H1. More generous donors will be more likely to publish both their name and the amount than to publish only their name or only the amount donated, or to publish none of this information, compared to less generous donors (enhancement theory).

$\mathrm{H} 2$. Average generous donors will be more likely to publish both their name and the amount than to publish only their name, only the amount donated, or to publish none of this information, compared to less or more generous donors (egalitarian theory).

The study also gave us the opportunity to investigate whether the amount collected by a runner was affected by the target distance and the target sum. It has previously been demonstrated that having a target amount itself can increase charity contributions, and donation rates increase as the sum collected approaches the funding target (Cryder et al. 2013). It was therefore hypothesized that a) fundraising runners who aim for a higher target sum will collect more donations. Furthermore, since long-distance running is a costly signal (and investment), we also hypothesized that b) runners who targeted a longer distance would collect more donations. Hence:

H3. The runner's target distance and target sum predicts the amount collected.

\section{METHOD}

The model system used was a charity sport community (www.elmenykulonitmeny.hu/en/), which collects donations for a foundation organizing recreation camps for seriously ill children (www.batortabor.hu/en/). The volunteers of this charity sport community undertake to run in a long-distance mass running race. Individuals or teams define a target sum to be reached through fundraising and invite their friends to donate to their run and thus to the recreation camp. The donations are transferred to the foundation through the personal webpage of the 


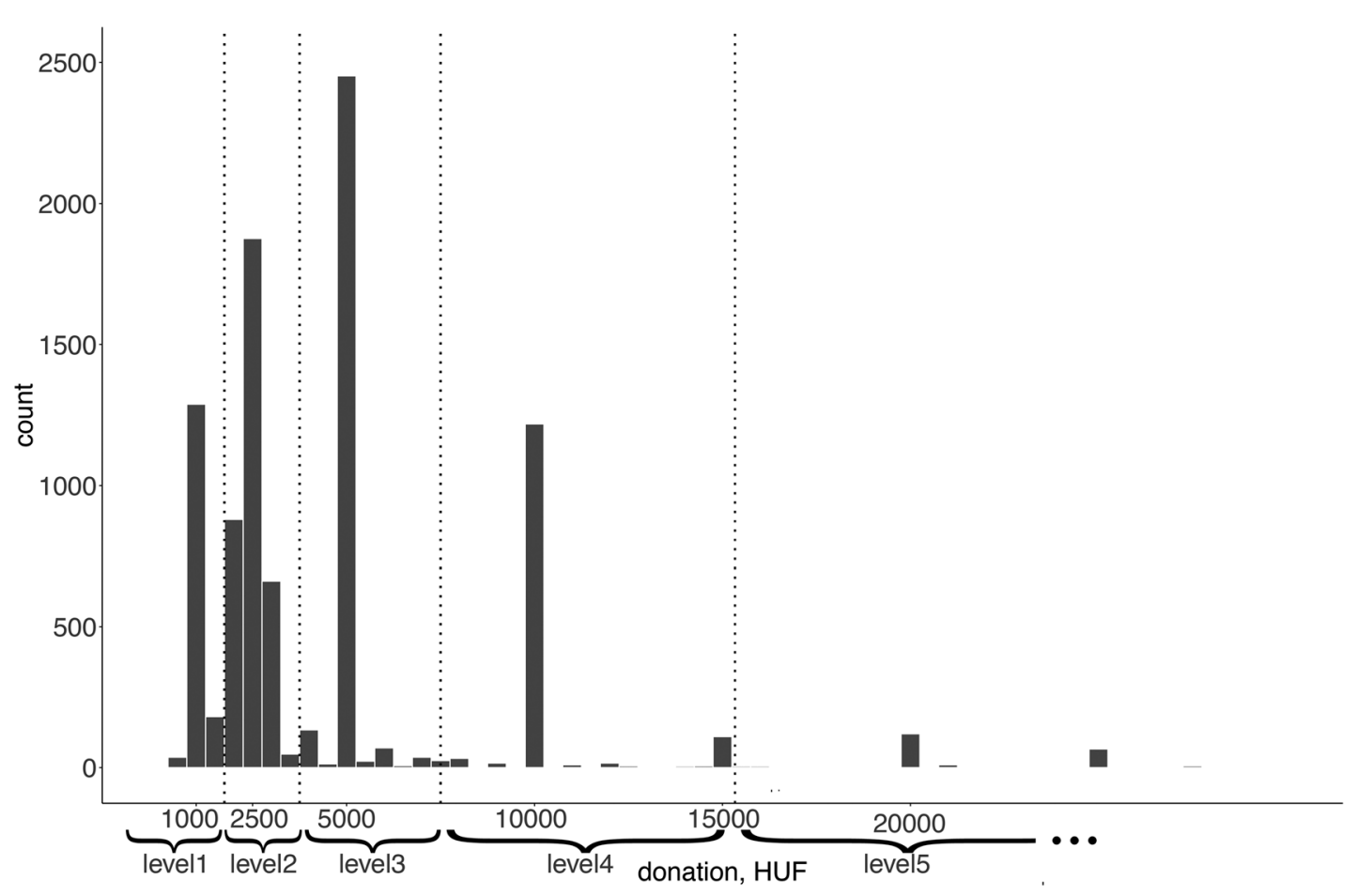

Figure 1. The distribution of the amounts donated. The dotted lines indicate the border of the categories created. The pre-determined amounts were $1000 \mathrm{HUF}, 2500 \mathrm{HUF}, 5000 \mathrm{HUF}$, and 10,000 HUF. The borders were decided on before the data analysis. The upper limit of level 5 is 227,000 HUF ( $\approx 691$ EUR), but the figure only shows the donations up to 30,000 HUF ( $\approx 91$ EUR) for the better visualization

runner. Donors can decide whether they want their names and the amount donated to be published on the webpage. Thus, there were 4 options: 1) publishing their name and the amount, 2) publishing only their name, 3) publishing only the amount they donated, and 4) publishing nothing. Information that was not published could not be seen by the runner or by any other visitor to the webpage. It was assumed that the runner and their potential and actual donors belong, in part at least, to the same peer group and monitor the webpage before and after donations. Therefore, a non-anonymous donation can affect the reputation of the donors and influence other potential donors.

Access to the sport community's database of online donations between 2012 and 2016 was secured. Fundraisers could enter a race individually or as relay teams. The target amount of individual runners was typically between 150,000 HUF $(\approx 456$ EUR $)$ and 250,000 HUF $(\approx 760$ EUR), while teams' targets fell between 150,000 HUF $(\approx$ 456 EUR) and 500,000 HUF ( $\approx 1521$ EUR). For the purposes of comparison, the average monthly salary after tax in Hungary in 2016 was 168,198 HUF $\approx 512$ EUR, according to the Hungarian Central Statistical Office (https://www.ksh.hu/docs/hun/xstadat/xstadat_evkozi/e_qli030a. html.)

The following data about the donations were available: 1) the amount donated, 2) whether the donor published their name, 3) whether the donor published the amount they donated, and 4) the identity of the runner or team who collected the donation. Concerning the runners/teams, two types of information were obtained: 1) the distance completed and 2) the target sum they wanted to achieve.
The actual sum collected by the runners and the teams was then calculated. In all, information concerning 9581 donation acts to 221 individual runners and 123 teams was at the disposal of the present study.

Donors had the option of donating 4 predetermined amounts $(1000 \mathrm{HUF} \approx 3$ EUR, $2500 \mathrm{HUF} \approx 8$ EUR, $5000 \mathrm{HUF} \approx 15 \mathrm{EUR}, 10,000 \mathrm{HUF} \approx 30 \mathrm{EUR})$, but were allowed to select any different amount. During the exploratory analyses, it was noted that the majority of the donors chose one of the pre-offered amounts (see Figure 1); therefore, categories based on these were created and used in statistical analyses (see below). The categories were defined as the arithmetic mean of the neighboring pre-offered amounts, and the following categories were created: level 1: 100-1750 HUF, level 2: 1751-3750 HUF, level 3: 3751-7000 HUF, level 4: 7001-15,000 HUF, and level 5: donations more than 15,000 HUF.

In order to study whether the choice of publishing only the name, publishing only the amount, publishing both the name and the amount, or publishing nothing were affected by the donated amount, the multinomial model was parameterized as a series of binomial contrasts (publishing both the name and the amount vs publishing only the name, publishing both the name and the amount vs publishing only the amount, and publishing both the name and the amount vs publishing nothing), and a series of general linear mixed models (GLMM) were fitted (Begg and Gray 1984; Agresti 2002), using the glmer function in the package lme4 in R (Bates 2010) with a binomial distribution of errors and a logit link function. In the first model, a subset of subjects who either published both their name and the amount or published only their name was 
used. The dependent variable was a binary variable where 0 represents publishing both the name and the amount, and 1 represents publishing only the name. In the second model, a subset of subjects who either published both their name and the amount or published only the amount was used, and the dependent variable was a binary variable where 0 represents publishing both the name and the amount, and 1 represents publishing only the amount. In the third model, a subset of subjects who either published both their name and the amount or published nothing was used, and the dependent variable was a binary variable where 0 represents publishing both the name and the amount, and 1 represents publishing nothing. In all of the models, the donated amount was set as explanatory variable and was treated as an ordered 5-level variable, as mentioned above. The identity of the runners/ teams was used as a random term to control for the effects of these repeated terms on the distribution of the data. Diagnostic plots were created to test the assumptions of the models. As a post-hoc test, the Tukey test was performed using the glht function in the multcomp package, to compare the donation categories to each other (Hothorn et al. 2008).

To investigate the effect of (i) the distance run and (ii) the target amount on the money collected, a linear model (LM) was employed. The amounts collected by individual runners and teams were set as response variables, while the distance run and the target amount were the explanatory variables. As the LM showed that both the distance of the run and the target amount have a significant positive effect on the money collected, the question is how do successful fundraisers achieve a higher amount. Using linear mixed models (LMMs), we investigated whether those who run a longer distance or have a higher target amount (i) have more donors and/or (ii) receive higher individual donations. To test whether running a longer distance leads to greater number of donors, the number of the donors to a particular team or individual runner was set as the response variable, and the distance as the explanatory variable. Group size (individual runners $=1$, team $=$ number of team members) was included in the model as random term. To test whether aiming for a higher target sum lead to greater number of donors, the number of the donors to a particular team or individual runner was set as the response variable, and the target amounts as the explanatory variable with group size included in the model as random term. To investigate whether higher individual donations lead to a higher amount collected, LMMs were once again used. The amount of individual donations, plotted on a log scale, was set as the response variable, while the distance or the target sum was used as the explanatory variables. The identity of the team/individual runner was included in the model as a random term. Diagnostic plots were then made to test the assumptions of the models.

\section{ETHICS}

This study does not require specific permission. The received and utilized data were completely anonymous.

\section{RESULTS}

The median donation was 3000 HUF (range: 100-227,000 HUF), with a mean of 5537 HUF \pm 8590 HUF, while the mode was 5000 HUF (see Figure 1).

Of the 9581 donations, $1476(15 \%)$ were completely anonymous, while in 4434 cases (46\%), donors published both their name and the amount donated; 2729 (28\%) donors published only their name, and 276 (3\%) donors published only the amount. Due to the problem with the online system, the option to remain anonymous was not available for 602 donations (8\%), so these data were excluded from the analysis of hypotheses 1 and 2 .

Are more generous donors more likely to publish their information?

No. Average level 3 donors are significantly more likely to publish both their names and the amounts than to publish none of this information, compared to less and more generous donors (GLMM and Tukey test, $p<0.01$, see Figure 2 and Table 1).

Less generous level 1 and level 2 donors are significantly more likely to publish only their names compared to level 3, level 4, or level 5 donors (as opposed to publishing both their names and the amounts) (GLMM and Tukey test, $p<0.01$, see Figure 2 and Table 1).

The most generous level 5 donors are significantly more likely to publish only the amounts than both their names and the amounts compared to level 1-4 donors (GLMM and Tukey test, $\mathrm{p}<0.01$, see Figure 2 and Table 1).

Is there a relationship between target and amount raised?

Yes. A longer running distance and a higher target amount have a positive effect on the collected donation (LM, $p<0.001$; see Figure 3 and Table 2). These effects are caused by the fact that fundraisers who run a longer distance or for a higher target amount receive higher individual donations (LMMs, $p=0.079, p=0.009$, respectively, see Table 3), but the number of donors does not change significantly with the running distance (LMMs, $p=0.635, p=0.699$, respectively, see Table 3).

\section{DISCUSSION}

The present study investigated the relationship between altruism and signaling in a real-world sample of charitable donors. We found that donors who gave an average amount are more likely to publish both their names and the amounts than to publish only their names, only the amounts, or none of this information, compared to aboveand below-average donors. Below-average donors are significantly more likely to publish only their names compared to any other donors. Very generous donors are significantly more likely to publish only the amount compared to any other donors. These results do not support the basic 'enhancement' theory of altruism (H1) but are partly consistent with the 'egalitarian' theory (H2; Raihani 2014).

Why might people be egalitarian rather than show-off? It has been shown earlier that individuals examine previous donations on the webpage for information about the 


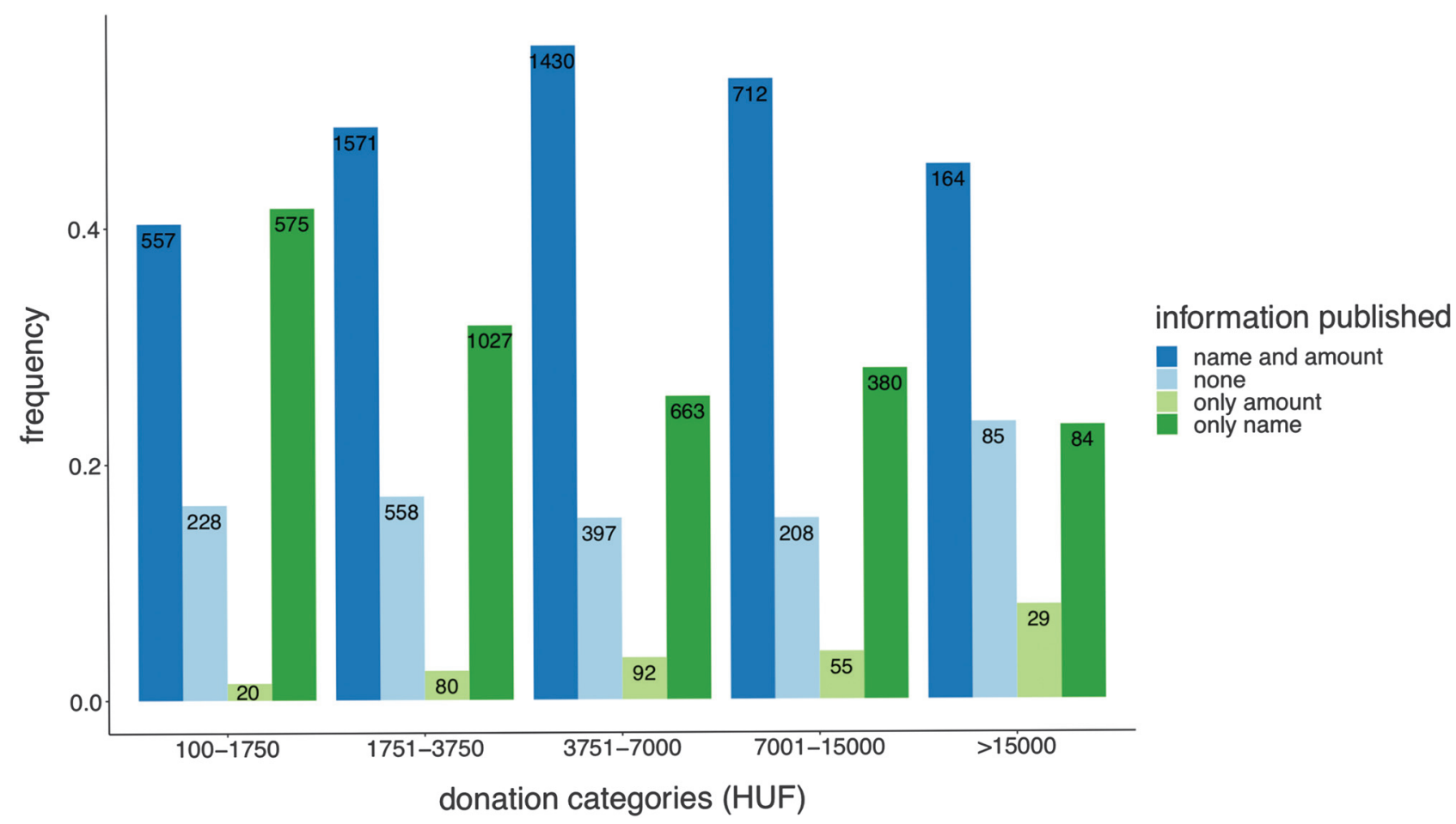

Figure 2. Donors' choice of information published for the different donation categories. The numbers above the bars indicate the number of donors in each category

Table 1. Pairwise comparison (Tukey test) of donation levels, as a post-hoc test of GLMMs: how the donors' willingness to publish their name and the amount donated is affected by the level of their contribution

\begin{tabular}{|c|c|c|c|c|c|c|c|c|c|c|c|c|}
\hline \multirow[b]{2}{*}{$\begin{array}{l}\text { Donation } \\
\text { categories }\end{array}$} & \multicolumn{4}{|c|}{$\begin{array}{l}\text { Publishing both the name and } \\
\text { the amount vs publishing only } \\
\text { the name }\end{array}$} & \multicolumn{4}{|c|}{$\begin{array}{l}\text { Publishing both the name and } \\
\text { the amount vs publishing only } \\
\text { the amount }\end{array}$} & \multicolumn{4}{|c|}{$\begin{array}{l}\text { Publishing both the name and } \\
\text { the amount vs publishing } \\
\text { nothing }\end{array}$} \\
\hline & $\begin{array}{c}\text { Estimate } \\
\text { (standard error) }\end{array}$ & $\begin{array}{c}Z \\
\text { value }\end{array}$ & $p$ & & $\begin{array}{c}\text { Estimate } \\
\text { (standard error) }\end{array}$ & $\begin{array}{c}Z \\
\text { value }\end{array}$ & $p$ & & $\begin{array}{c}\text { Estimate } \\
\text { (standard error) }\end{array}$ & $\begin{array}{c}Z \\
\text { value }\end{array}$ & $p$ & \\
\hline el 1 & $-0.66(0.08)$ & -7.84 & $<0.001$ & $* * *$ & $0.21(0.27)$ & 0.77 & 1 & & -0.28 & -2.66 & 0.078 & \\
\hline 11 & $-1.08(0.09)$ & -12.01 & $<<0.001$ & $* * *$ & 0.52 & 1.91 & 0.559 & & -0.57 & -5.1 & $<<0.001$ & $* * *$ \\
\hline evel 4-level 1 & $-0.94(0.10)$ & -9.02 & $<<0.001$ & $* * *$ & $0.68(0.29)$ & 2.33 & 0.198 & & $-0.52(0.13)$ & -4.02 & $<0.01$ & $* * *$ \\
\hline vel 1 & $-1.02(0.17)$ & -5.91 & $<<0.001$ & $* * *$ & 1.44 & 4.12 & $<0.001$ & $* * *$ & -0.03 & -0.16 & 1 & \\
\hline level 3- level 2 & $-0.42(0.07)$ & -5.94 & $<<0.001$ & $* * *$ & $0.31(0.17)$ & 1.78 & 0.75 & & $-0.29(0.08)$ & -3.42 & 0.006 & $* *$ \\
\hline level 4- level 2 & $-0.27(0.09)$ & -3.15 & 0.016 & $*$ & $0.47(0.20)$ & 2.32 & 0.201 & & $-0.23(0.10)$ & -2.21 & 0.27 & \\
\hline level 5- level 2 & $-0.36(0.16)$ & -2.22 & 0.262 & & $1.23(0.28)$ & 4.39 & $<0.001$ & $* * *$ & $0.25(0.17)$ & 1.52 & 1 & \\
\hline level 4- level 3 & $0.15(0.09)$ & 1.64 & 0.997 & & $0.16(0.19)$ & 0.83 & 1 & & $0.06(0.11)$ & 0.53 & 1 & \\
\hline level 5- level 3 & $0.06(0.16)$ & 0.37 & 1 & & $0.93(0.28)$ & 3.36 & 0.008 & $* *$ & $0.54(0.17)$ & 3.25 & 0.001 & * \\
\hline level 5- level 4 & $-0.09(0.17)$ & -0.51 & 1 & & $0.77(0.29)$ & 2.61 & 0.089 & & $0.49(0.18)$ & 2.75 & 0.059 & \\
\hline Level 1: 100-17 & HUF, level 2 & 30 & & & $751-7000 \mathrm{H}$ & & & & 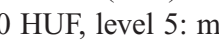 & & & \\
\hline
\end{tabular}

Number of asterisks show the level of significance (“*” $<0.05$, “**” $<0.01$, “***” $<0.001$ ). “.” shows 0.1 level of significance.

donation behavior of others before themselves donating (Smith et al. 2015). Donors give what they think that they personally are expected to give on the basis of the distribution of the donations of their peers, plus other factors, such as their income and relationship with the fundraiser. While there are donors giving very high and low donations, most donors tend to make donations on the basis of the already existing modal value (Smith et al. 2015). In the light of these results, it is probable that donors who deviate from the expected behavior by giving very low or very high donations tend to mask their norm-violating acts. A potential explanation of the below-average donors' preference for publishing only their names might be that they know that their donations are small compared to the others in the peer group, so they dissemble their less generous act by donating a small but masked amount and publishing their identity. This strategy still helps to enhance the reputation of the donor, while requiring limited expense. This makes it a type of free-rider strategy, since these donors receive the same social benefit as average donors but invest significantly less. Donors giving extremely high donations are also likely to receive social punishment. Investigations have demonstrated that verbal and non-verbal boasting or showing off generates strong 


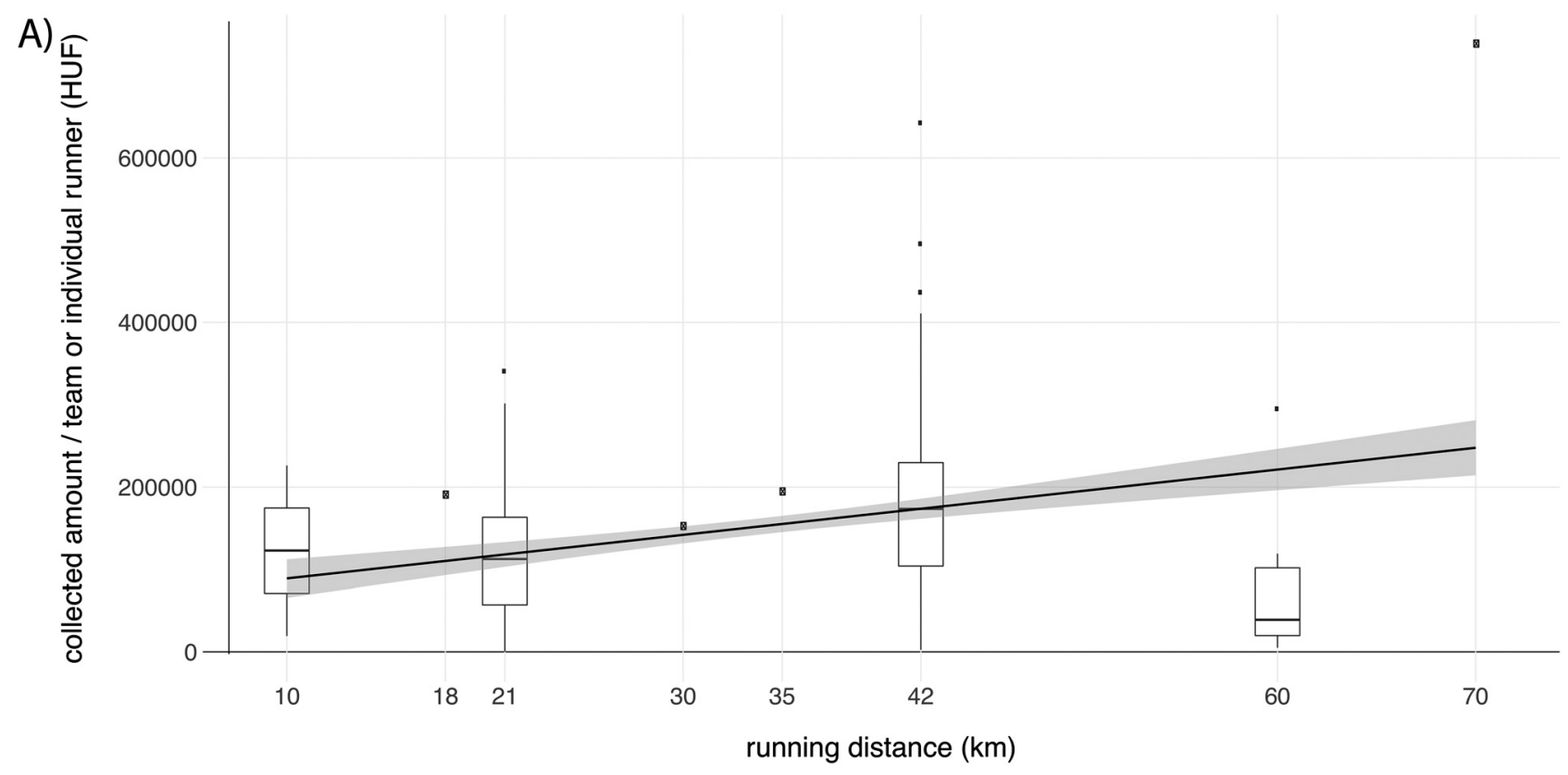

B)

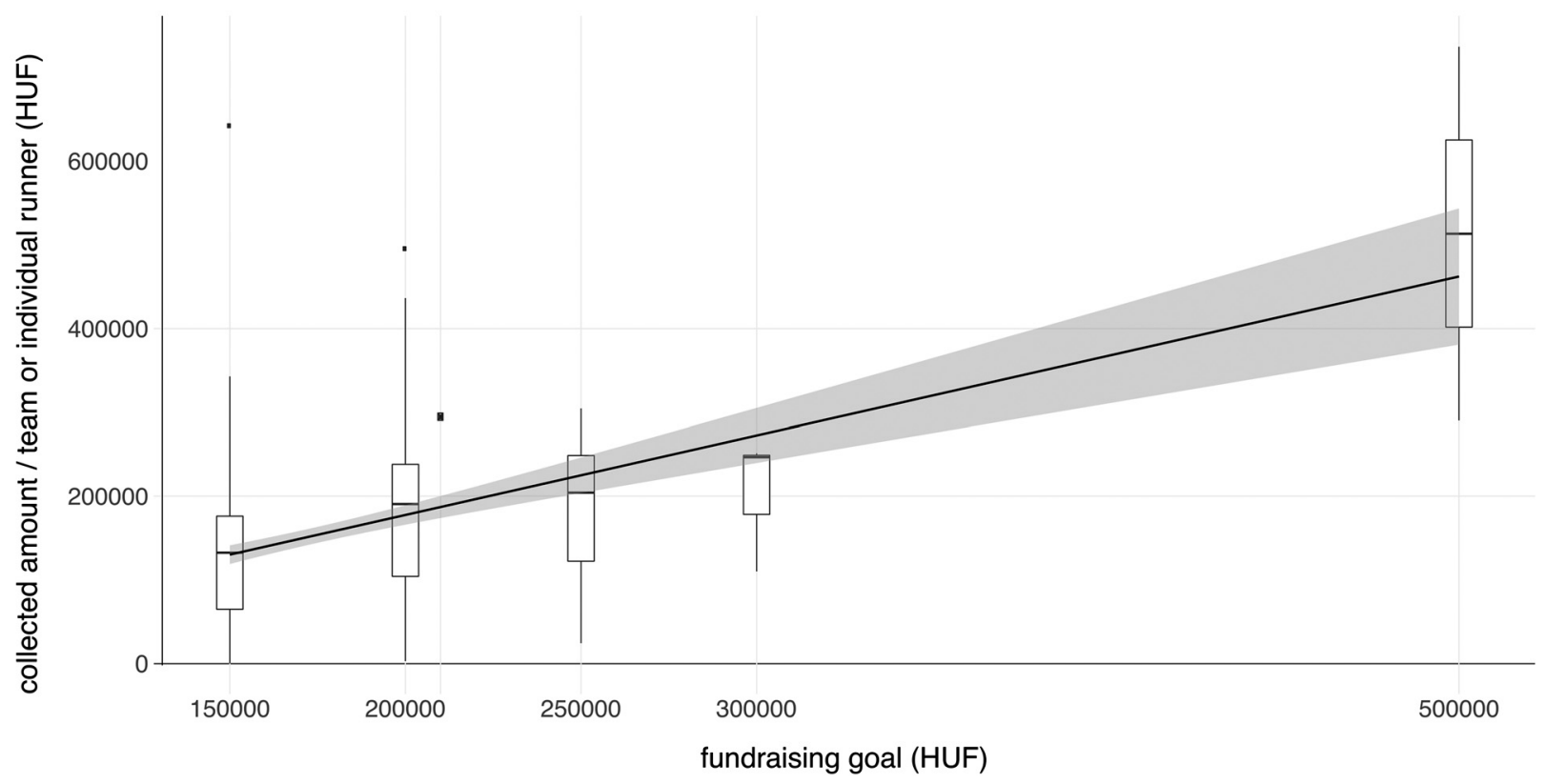

Figure 3. Amount of money collected by individual runners and teams according to A) distance run and B) fundraising goal. The regression line and $95 \%$ confidence intervals are shown

negative emotions in peers, i.e., displeasure (Fisher et al. 1982), suspiciousness (Herrmann et al. 2008), and envy (Monin 2007).

Table 2. A longer running distance and a higher target amount have a positive effect on the collected donation. These results come from the application of a Linear Model

\begin{tabular}{lcccccc}
\hline & Value & Std. error & Df & $t$-value & $p$ \\
\hline Intercept & -36740 & 23050 & -1.60 & -1.59 & 0.11 \\
Running distance (km) & 1629 & 465.4 & 3.50 & 3.50 & $<<0.001^{* * *}$ \\
Target amount (HUF) & 0.77 & 0.13 & 5.76 & 5.76 & $<<0.001^{* * *}$ \\
\hline
\end{tabular}

The question arises as to why a significant proportion of donors giving extremely high donations hide their names but reveal the amount of the donation. The motivation of these donors can be to support the aim of the foundation or the high reputation of the runner with a large amount of money. For these donors, any potential reputation gain is not a priority when they decide their anonymity request (Reinstein \& Riener 2012). Visible high donations could function as a quality signal for the charitable goal (Vesterlund 2003) and/or for the runner (Smith et al. 2015). However, it cannot be excluded that these donors inform the runner and even other peers about their identity by different channels of communication (phone, email etc.). 
Table 3. Fundraisers who run a longer distance or target a higher amount collect a greater amount because they receive larger donations from the same number of donors. These are the results of linear mixed models

\begin{tabular}{|c|c|c|c|c|c|c|}
\hline Model & & Value & Std. error & Df & $t$-value & $p$ \\
\hline Number of donors $\sim$ distance & Intercept & 31.894 & 4.805 & 9.859 & 6.638 & $<<0.001$ \\
\hline Random effect: group size & Distance & 0.043 & 0.090 & 330.4 & 0.475 & 0.635 \\
\hline Number of donors $\sim$ target amount & Intercept & 36.05 & 7.257 & 1.942 & 4.968 & $<<0.001$ \\
\hline Random effect: group size & Target amount & $<0.001$ & $<0.001$ & 0.018 & -0.387 & 0.699 \\
\hline $\log ($ donation $) \sim$ distance & Intercept & 8.134 & 0.058 & 0.003 & 141.13 & $<<0.001$ \\
\hline Random effect: ID of runner/team & Distance & 0.002 & 0.001 & 0.003 & 1.761 & 0.079 \\
\hline $\log ($ donation $) \sim$ target amount & Intercept & 8.03 & 0.008 & 0.002 & 98.05 & $<<0.001$ \\
\hline Random effect: ID of runner/team & Target amount & $<0.001$ & $<0.01$ & 0.002 & 2.616 & 0.009 \\
\hline
\end{tabular}

It was also found that running a longer distance or having a higher target amount helps collecting higher donations. It is known from earlier works that donation activity increases as the sum of the donation approaches the target amount and relaxes after it reaches the target (Cryder et al. 2013; Smith et al. 2015). According to the results of the present study, the target amount is a direct motivating factor, at least within the studied range, and this is caused primarily through higher individual donations, and not by having more donors.

The long-distance run demonstrates a real investment on the part of the runner, and this is probably perceived as a costly signal in the eyes of potential donors about the runner's commitment to the aims of the foundation. Most of the runners need some considerable amount of continuous training before the event, which is more pronounced if somebody runs a longer distance. This investment reliably informs others about the motivation of the runner toward the altruistic goal of the foundation and therefore increases the reputation of the runner. On the personal webpage, there is an option to write short messages to the runner. According to these messages, donors frequently consider running as a real altruistic act and emphasize the high reputation of the runner (writing, for example, "I'm proud of you, you are amazing"). It would seem clear that the reputation gain of the runner correlates with the level of investment, so the propensity to donate increases with the runner's investment, too.

To the best of the authors' knowledge, this study is the first to show that fundraisers who signal their commitment to a socially supported aim collect higher donations if their signal is costlier from a physical perspective.

Although the different donation and signaling strategies were revealed and hypotheses concerning the psychological background of the results have been suggested, further investigation is required to reveal the real motivation of donors. Why do donors giving extremely high and low donations behave differently? Why do they more readily donate to fundraisers who signal costlier investment of effort? To answer these questions, compilation of a specific questionnaire for donors and analysis of the short messages that they send are planned. In addition, further well-designed lab-based studies are needed to understand more deeply the relationship between human altruism and reputation management.

\section{FUNDING}

This work was supported by the National Scientific Research Fund (OTKA K128289) and by the Hungary's Economic Development and Innovation Operative Program (GINOP 2.3.2-15-2016-00057).

\section{AUTHORS' CONTRIBUTION}

IS designed the research, and JM collected and analyzed the data. The authors discussed the results and wrote the paper together.

\section{CONFLICT OF INTERESTS}

We have no competing interests.

\section{SUPPORTING INFORMATION}

Supporting Information with the dataset of the analysis is available as an ESM file.

Acknowledgments: The authors thank István Hahn, Sophie Miller, János Podani, Zsóka Vásárhelyi, and José Valdebenito for their useful comments on the manuscript. We also thank the Bátor Tábor Foundation for sharing their database with us. We are grateful to the reviewer and the editor for the constructive feedback.

\section{REFERENCES}

Aiello, L. C., \& Dunbar, R. I. M. (1993). Neocortex size, group size, and the evolution of language. Curr. Anthropol., 34, 184-193. doi: 10.1086/204160s.

Agresti, A. (2002). Categorical data analysis (2nd ed.). Hoboken, NJ: John Wiley \& Sons. doi: 10.1002/ 0470114754.

Arnocky, S., Piché, T., Albert, G., Ouellette, D., \& Barclay, P. (2016). Altruism predicts mating success in humans. Br. J. Psychol., 108, 416-435. doi: 10.1111/bjop.12208. 
Bahry, D. L., \& Wilson, R. K. (2006). Confusion or fairness in the field? Rejections in the ultimatum game under the strategy method. J. Econ. Behav. Organ., 60, 37-54. doi: 10.1016/j.jebo.2004.07.005.

Bates, D. M. (2010). Fitting linear mixed-effects models using Ime4. J. Stat. Software, 67, 1-48. doi: 10.1177/ 009286150103500418.

Bateson, M., Nettle, D., \& Roberts, G. (2006). Cues of being watched enhance cooperation in a real-world setting. Biol. Lett., 2, 412-414. doi: 10.1098/rsbl.2006.0509.

Begg, C. B., \& Gray, R. (1984). Calculation of polychotomous logistic regression parameters using individualized regressions. Biometrika, 71, 11-18.

Bereczkei, T., Birkas, B., \& Kerekes, Z. (2007). Public charity offer as a proximate factor of evolved reputation-building strategy: an experimental analysis of a real-life situation. Evol. Hum. Behav., 28, 277-284. doi: 10.1016/j. evolhumbehav.2007.04.002.

Bereczkei, T., Birkas, B., \& Kerekes, Z. (2010). Altruism towards strangers in need: costly signaling in an industrial society. Evol. Hum. Behav., 31, 95-103. doi: 10.1016/j. evolhumbehav.2009.07.004.

Clutton-Brock, T. (2009). Cooperation between non-kin in animal societies. Nature, 462, 51-57. doi: 10.1038/nature08366.

Cryder, C. E., Loewenstein, G., \& Seltman, H. (2013). Goal gradient in helping behavior. J. Exp. Soc. Psychol., 49, 1078-1083. doi: 10.1016/j.jesp.2013.07.003.

Cuesta, J. A., Gracia-Lázaro, C., Ferrer, A., Moreno, Y., \& Sánchez, A. (2015). Reputation drives cooperative behaviour and network formation in human groups. Sci. Rep., 5, 1-6. doi: 10.1038/srep07843.

Dawes, C. T., Fowler, J. H., Johnson, T., McElreath, R., \& Smirnov, O. (2007). Egalitarian motives in humans. Nature, 446, 794-796. doi: 10.1038/nature05651.

Ekström, M. (2011). Do watching eyes affect charitable giving? Evidence from a field experiment. Exp. Econ., 15, 530-546. doi: 10.1007/s10683-011-9312-6.

Engelmann, D., \& Fischbacher, U. (2008). Indirect reciprocity and strategic reputation building in an experimental helping game. J. Math. Sci., 145, 4765-4772. doi: 10.1007/s10958007-0307-y.

Ernest-Jones, M., Nettle, D., \& Bateson, M. (2011). Effects of eye images on everyday cooperative behavior: A field experiment. Evol. Hum. Behav., 32, 172-178. doi: 10.1016/j. evolhumbehav.2010.10.006.

Fisher, J. D., Nadler, A., \& Whitcher-Alagna, S. (1982). Recipient reactions to aid. Psychol. Bull., 91, 27-54. doi: 10.1037/0033-2909.91.1.27.

Fowler, J. H., Johnson, T., \& Smirnov, O. (2005). Egalitarian Motive and Altruistic Punishment, 140, 2005. doi: 10.1038/ nature 03256.

Francey, D., \& Bergmüller, R. (2012). Images of eyes enhance investments in a real-life public good. PLoS ONE, 7, e37397. doi: 10.1371/Journal.pone0037397.

Gintis, H., Bowles, S., Boyd, R., \& Fehr, E. (2003). Explaining altruistic behavior in humans. Evol. Hum. Behav., 24, 153172. doi: 10.1016/S1090-5138(02)00157-5.

Hagen, E. H., \& Hammerstein, P. (2006). Game theory and human evolution: A critique of some recent interpretations of experimental games. Theor. Popul. Biol., 69, 339-348. doi: 10.1016/j.tpb.2005.09.005.
Haley, K. J., \& Fessler, D. M. T. (2005). Nobody's watching? Subtle cues affect generosity in an anonymous economic game. Evol. Hum. Behav., 26, 245-256. doi: 10.1016/j. evolhumbehav.2005.01.002.

Hamilton, M. J., Milne, B. T., Walker, R. S., Burger, O., \& Brown, J. H. (2007). The complex structure of huntergatherer social networks. Proc. Biol. Sci., 274, 2195-2202. doi: $10.1098 / \mathrm{rspb} .2007 .0564$.

Hardy, C. L., \& Van Vugt, M. (2006). Nice guys finish first: The competitive altruism hypothesis. Pers. Soc. Psychol. Bull., 32, 1402-1413. doi: 10.1177/0146167206291006.

Henrich, J., Heine, S. J., \& Norenzayan, A. (2010). Most people are not WEIRD. Nature, 466, 20. doi: 10.1017/ S0140525X0999152X.

Herrmann, B., Thöni, C., \& Gächter, S. (2008). Antisocial punishment across societies. Science, 319, 1362-1367. doi: 10.1126/science. 1153808 .

Hill, R. A., \& Dunbar, R. I. M. (2002). Social network size in humans. Hum. Nat., 14, 53-72. doi: 10.1007/s12110-003-1016-y.

Hothorn, T., Bretz, F., \& Westfall, P. (2008). Simultaneous inference in general parametric models. Biom. J., 50, 346363. doi: 10.1002/bimj.200810425.

Irwin, K., \& Horne, C. (2013). A normative explanation of antisocial punishment. Soc. Sci. Res., 42, 562-570. doi: 10.1016/j.ssresearch.2012.10.004.

Jacquet, J., Hauert, C., Traulsen, A., \& Milinski, M. (2011). Shame and honour drive cooperation. Biol. Lett., 7, 899-901. doi: 10.1098/rsbl.2011.0367.

Kaplan, H. S., \& Hill, K. (1985). Hunting ability success among male ache foragers: Preliminary results. Curr. Anthropol., 26, 131-133. doi: 10.1086/203235.

Knafo, A., Schwartz, S. H., \& Levine, R. V. (2009). Helping strangers is lower in embedded cultures. J. Cross-Cultural Psychol., 40, 875-879. doi: 10.1177/0022022109339211.

Kurzban, R. (2001). The social psychophysics of cooperation: Nonverbal communication in a public goods game. J. Nonverbal Behav., 25, 241-259. doi: 10.1023/A:1012563421824.

List, J. A., \& Levitt, S. D. (2005). What do laboratory experiments tell us about the real world? Unpublished Manuscript. Retrieved from http://pricetheory.uchicago.edu/ levitt/Papers/LevittList2005.pdf.

List, J. A., \& Lucking-Reiley, D. (2002). The effects of seed money and refunds on charitable giving: experimental evidence from a university capital campaign. J. Polit. Econ., 110, 215-233. doi: 10.1155/2017/5789714.

Milinski, M. (2016). Reputation, a universal currency for human social interactions. Philos. Trans. R. Soc., B, 371, 20150100. doi: 10.1098/rstb.2015.0100.

Milinski, M., Semmann, D., Bakker, T. C. M., \& Krambeck, H.J. (2001). Cooperation through indirect reciprocity: Image scoring or standing strategy?. Proc. R. Soc. B, 268, 24952501. doi: 10.1098/rspb.2001.1809.

Milinski, M., Semmann, D., \& Krambeck, H.-J. (2002a). Donors to charity gain in both indirect reciprocity and political reputation. Proc. R. Soc. B, 269, 881-883. doi: 10.1098/ rspb.2002.1964.

Milinski, M., Semmann, D., \& Krambeck, H.-J. (2002b). Reputation helps solve the "tragedy of the commons". Nature, 415, 424-426. doi: 10.1038/415424a.

Monin, B. (2007). Holier than me? Threatening social comparison in the moral domain. Rev. Int. Psychol. Soc., 20, 
53-68. Retrieved from https://www.cairn.info/revueinternationale-de-psychologie-sociale-2007-1-page-53.htm.

Nakamaru, M., \& Kawata, M. (2004). Evolution of rumours that discriminate lying defectors. Evol. Ecol. Res., 6, 261-283. Retrieved from http://www.evolutionary-ecology.com/issues/ v06n02/iiar1593.pdf.

Northover, S. B., Pedersen, W. C., Cohen, A. B., \& Andrews, P. W. (2017). Artifical surveillance cues do not increase generosity: two meta-analyses. Evol. Hum. Behav., 38, 144 153. doi: 10.1016/j.evolhumbehav.2016.07.001.

Nowak, M. A. (2006). Five rules for the evolution of cooperation. Science, 1560, 1560-1563. doi: 10.1126/ science.1133755.

Nowak, M. A., \& Sigmund, K. (1998). Evolution of indirect reciprocity by image scoring. Nature, 393, 573-577. doi: $10.1038 / 31225$.

Nowak, M. A., \& Sigmund, K. (2005). Evolution of indirect reciprocity. Nature, 437, 1291-1298. doi: 10.1038/nature04131.

Ohtsuki, H., Iwasa, Y., \& Nowak, M. A. (2015). Reputation effects in public and private interactions. PLoS Comput. Biol., 11, 1-11. doi: 10.1371/journal.pcbi.1004527.

Parks, C. D., \& Stone, A. B. (2010). The desire to expel unselfish members from the group. J. Pers. Soc. Psychol., 99, 303-310. doi: 10.1037/a0018403.

Post, S. G. (2005). Altruism, happiness, and health: It's good to be good. Int. J. Behav. Med., 12, 66-77. doi: 10.1207/ s15327558ijbm1202.

Raihani, N. J. (2014). Hidden altruism in a real-world setting. Biol. Lett., 10. doi: 10.1098/rsbl.2013.0884.

Raihani, N. J., \& Smith, S. (2015). Competitive helping in online giving. Curr. Biol., 25, 1183-1186. doi: 10.1016/j. cub.2015.02.042.
Reinstein, D., \& Riener, G. (2012). Reputation and influence in charitable giving: An experiment. Theor. Decis., 72, 221243. doi: 10.1007/s11238-011-9245-8.

Seinen, I., \& Schram, A. (2001). Social status and group norms: Indirect reciprocity in a helping experiment. Unkown Publisher. Retrieved from https://dare.uva.nl/search? identifier=723f3b9c-97ea-4288-a057-06081f570f06.

Shreeves, G., \& Field, J. (2002). Group size and direct fitness in social queues. Am. Nat., 159, 81-95. doi: 10.1086/324125.

Smith, S., Windmeijer, F., \& Wright, E. (2015). Peer effects in charitable giving: Evidence from the (running) field. Econ. $J ., 125,1053-1071$. doi: 10.1111/ecoj.12114.

Sznycer, D., Xygalatas, D., Alami, S., An, X.-F., Ananyeva, K. I., Fukushima, S., Tooby, J. (2018). Proc. Natl. Acad. Sci. U. S. A., 201808418. doi: 10.1073/pnas.1808418115.

Vesterlund, L. (2003). The informational value of sequential fundraising. J. Public Econ., 87, 627-657. doi: 10.1016/ S0047-2727(01)00187-6.

Voors, M., Turley, T., Kontoleon, A., Bulte, E., \& List, J. A. (2012). Exploring whether behavior in context-free experiments is predictive of behavior in the field: Evidence from lab and field experiments in rural Sierra Leone. Econ. Lett., 114, 308-311. doi: 10.1016/j.econlet.2011.10.016.

Wedekind, C., \& Braithwaite, V. A. (2002). The long-term benefits of human generosity in indirect reciprocity. Curr. Biol., 12, 1012-1015.

Wedekind, C., \& Milinski, M. (2000). Cooperation through image scoring in humans. Science, 288, 850-852. doi: 10.1126/science.288.5467.850.

Winking, J., \& Mizer, N. (2013). Natural-field dictator game shows no altruistic giving. Evol. Hum. Behav., 34, 288-293. doi: 10.1016/j.evolhumbehav.2013.04.002. 